\title{
Local scour at a bridge abutment along a curved channel
}

\author{
MERAL KORKMAZ ${ }^{1}$ and M. EMIN EMIROGLU ${ }^{2}$ \\ ${ }^{1}$ Munzur Universitesi \\ ${ }^{2}$ Firat Universitesi
}

June 1, 2020

\begin{abstract}
Previous studies have generally focused on abutments located on a straight channel. Few have focused on curved channels. The present study comprised an experimental examination of the local scour that occurs around different length abutments placed on the inner and outer banks along a curved channel in a clear-water scour flow condition. The local scour around an abutment in a curved channel is a function of the upstream Froude number, flow intensity, the angle of bend curvature, and the ratios of abutment length to flow depth, abutment length to abutment width, and abutment length to channel width. The maximum scour depth around the abutments placed on the outer bank was found to be 1.45 times the scour depth on the inner bank. An empirical equation was developed to consider all dimensional parameters for equilibrium scour depth. The average percent error of the proposed equation was $2 \%$.
\end{abstract}

\begin{abstract}
Previous studies have generally focused on abutments located on a straight channel. Few have focused on curved channels. The present study comprised an experimental examination of the local scour that occurs around different length abutments placed on the inner and outer banks along a curved channel in a clearwater scour flow condition. The local scour around an abutment in a curved channel is a function of the upstream Froude number, flow intensity, the angle of bend curvature, and the ratios of abutment length to flow depth, abutment length to abutment width, and abutment length to channel width. The maximum scour depth around the abutments placed on the outer bank was found to be 1.45 times the scour depth on the inner bank. An empirical equation was developed to consider all dimensional parameters for equilibrium scour depth. The average percent error of the proposed equation was $2 \%$.
\end{abstract}

Keywords : Scour, bridge abutment, curved channel, clear-water scour, flow intensity.

${ }^{1}$ Assistant Professor, Dept. of Civil Engineering, Munzur Univ., ", 62100, Turkey (corresponding author). E-mail:meralkorkmaz@munzur.edu.tr

${ }^{2}$ Professor, Dept. of Civil Engineering, Firat Univ., Elazig 23100, Turkey. E-mail:memiroglu@firat.edu.tr

\section{Introduction}

Bridges constructed to rapidly and reliably conduct intercity transportation are urgently needed, along with an increase in transportation requirements. However, destruction or damage to bridges causes loss of life and property and negatively affects the flow of life. One of the most important reasons for the collapse of bridges is scouring (Barbhuiya and Dey, 2004). A riverbed in the vicinity of a hydraulic structure is generally protected against current, waves, and eddies (Azamathulla, 2012). Scouring can occur at any time due to the flow of the stream, but is more likely to occur during floods. Scouring is a complex phenomenon resulting from the three-dimensional powerful interaction between the scouring mechanism and flow type around the 
bridge abutments and piers, erodible bed material, and the turbulence flow around the bridge foundation. Figure 1 shows the flow and scour pattern at an abutment.

Fig. 1. Flow and scour pattern around an abutment

Rosgen (1994) identified seven major categories of stream that differ in terms of entrenchment, gradient, width/depth ratio, and sinuosity in various landforms. Based on both static and dynamic characteristics, streams can be classified as follows: (1) straight streams (sinuosity $<1.1),(2)$ braided stream $\left(\tilde{B}^{0.5} \geq F_{1}\right)$, and (3) meandering streams (sinuosity $>1.5$ ), in which $\tilde{B}\left(=B . S_{o} / h_{d}\right)$ is the nondimensional parameter, $B$ is the average river width, $h_{d}$ is the hydraulic depth, $S$ o is the bed slope, and $\mathrm{F}_{1}$ is the Froude number. Straight streams generally flow with a minimal number of turns. Most are meandering rivers as long straight streams are rare (Leopold and Wolman, 1957). The curve or curvature on an open channel creates additional flow resistance similar to that caused by bridge abutments placed on linear channels or by an increase in channel roughness. This change in flow resistance results in increased depth and reduced flow rate in the upstream. The backwater pressure effect is more pronounced at sharp curves that occur at the boundary layer separation of the outer bank near the downstream. Depending on the radius of the curve, a transverse inclination is formed on the water surface.

The problem of scouring is significant and has been investigated for many years. For instance, DamaskinidouGeorgiadou and Smith (1986) experimentally examined the velocity distribution in a curved canal. All their experiments demonstrated that maximum longitudinal velocities occurred in the inside bank, and it was the approach of the vertical mean velocity distribution along the channel width. Based on tests conducted over a long period of time, Melville (1992) classified the equilibrium scour depth $\left(d_{s e}\right)$ based on flow depth and abutment length. If $L_{a} / y$ [?] 1 , it is known as short abutment; whereas if $L_{a} / y$ [?] 25, it is known as long abutment. The equation proposed by Melville (1992) to predict equilibrium scour depth (taking into account abutment length and approach flow depth) is:

$d_{\text {se }}=2 \cdot K_{s} \cdot L_{a} \quad$ for $\quad \frac{L_{a}}{y} \leq 1(1)$

where $d_{s e}$ is the equilibrium scour depth, $K_{s}$ is the shape factor of the abutment, $L_{a}$ is the abutment length, and $y$ is the approach flow depth. Melville (1992) stated that $K_{s}$ is 0.75 for a vertical wall with a semicircular end. Thus, $d_{s e}$ is equal to1.50L $L_{a}$.

Urroz et al. (1994) studied the ice conveyance of a bridge location in a sinuous channel $0.254 \mathrm{~m}$ wide, 0.203 $\mathrm{m}$ deep, and with a radius of curvature of $0.92 \mathrm{~m}$, while Kandasamy and Melville (1998) investigated the maximum scour depth that could occur at bridge abutments and piers. Cardoso and Bettess (1999) then studied the effects of time and channel geometry on scouring in bridge abutments. Oliveto and Hager (2002) proposed Eq. (2) for time-dependent scour depth at a vertical wall abutment.

$\frac{d_{\mathrm{se}}}{L_{R}}=0.085 \sigma_{g}^{-0.5} F_{d}^{1.5} \log T_{d}(2)$ in which $L_{R}=L_{a}{ }^{2 / 3} y^{1 / 3}, F_{d}=V /\left(g d_{50}\right)^{0.5}, T_{d}=t / t_{R}$, and $t_{R}=L_{R} /\left(g d_{50}\right)^{0.5}$ , where $\mathrm{F}_{d}$ is the densimetric Froude number, $\mathrm{V}$ is the mean approach flow velocity, $\sigma_{\gamma}$ is the geometric standard deviation of the sediment $\left(\sigma_{g}=\left(d_{84.1} / d_{15.9}\right)^{0.5}\right), d_{84.1}$ is the particle diameter for which $84.1 \%$ of the sediment is finer, $d_{15.9}$ is the particle diameter for which $15.9 \%$ of the sediment is finer, $t$ is time, $d_{50}$ is the mean grain size, $g$ is the acceleration due to gravity, $\Delta$ is equal to $\left(\rho_{S} / \rho\right)-1=\left(\rho_{S}-\rho\right) / \rho=\rho_{S}^{\prime} / \rho, \rho_{S}$ is the mass density of sediment particles, and $\rho$ is the mass density of water.

Lim (1997) proposed an empirical equation of maximum equilibrium scour depth for vertical wall abutments, as shown in Eq. (3). This includes dimensionless maximum equilibrium scour depth and dimensionless length of abutment.

$\frac{d_{\mathrm{se}}}{y}=1.8\left(\frac{L_{a}}{y}\right)^{0.5}(3)$

Coleman et al. (2003) investigated the scours formed around the bridge abutment under clear-water flow conditions while Seckin (2004) investigated bridge constrictions in a compound channel. The author proposed an empirical equation to estimate the backwater at bridge constrictions in compound channels with an overbank flow. Dey and Barbhuiya (2005) presented a semi-empirical model to determine the time variation 
of scour depth for $L_{a} / y$ [?] 1. The authors proposed Eq. (4) to calculate the equilibrium scour depth for semicircular abutment.

$\frac{d_{\text {se }}}{L_{a}}=8.689 F_{e}^{0.192}\left(\frac{y}{L_{a}}\right)^{0.103}\left(\frac{L_{a}}{d_{50}}\right)^{-0.296}$

in which $\mathrm{F}_{e}$ is the excess abutment Froude number, which $V_{e} /\left(\Delta \gamma \Lambda_{a}\right)^{0.5} \cdot V_{e}=V-\xi_{S}^{\prime \prime}$ and $\Delta=\left(\rho_{S} / \rho\right)-1$. $V$ is the average approaching flow velocity, and $V_{c}$ is the critical velocity for sediment particles. The value of $\xi$ is 0.6 for semicircular abutment.

Rajkumar and Dey (2005) conducted experiments using uniform and non-uniform sediments to investigate clear-water scouring in circular and square bridge piers and the time taken to reach the scour depth equilibrium. Their results showed that equilibrium depth was inversely proportional to the particle diameter. Furthermore, the time required for scour depth equilibrium on bridge abutments increased with the Froude number and particle diameter for uniform material and decreased in line with a decrease in the geometrical standard deviation of particle diameter distribution for non-uniform bed material.

Kayaturk (2005) investigated the local scouring around a bridge abutment. The study was conducted in a 30 $\mathrm{m}$ long and $1.5 \mathrm{~m}$ wide open channel. The test channel was filled with uniform bed material with a median particle diameter of $d_{50}=1.48 \mathrm{~mm}$. The sand depth was $0.5 \mathrm{~m}$ at the bridge abutment. Kayaturk reported that the lateral abutment length was a more significant parameter than the abutment width. The results showed that the scour depth was reduced when the width of the plates placed at different depths around the bridge abutments to reduce the local scour depth increased, and when the plate was placed at or below sand level. Kothyari et al. (2007) proposed a formula to calculate the time-based development of clear-water scouring. Experiments were conducted on two separate $11 \mathrm{~m}$ long rectangular channels of $1 \mathrm{~m}$ and $0.50 \mathrm{~m}$ width, respectively. Yanmaz and Kose (2007) conducted an experimental investigation into the clear-water scour around a rectangular cross section bridge abutment using uniform bed material. They measured the scour depth and contour, and provided the spatial and volumetric changes in the scour that formed around the bridge abutment. Based on the results, they proposed a placement location for the riprap to prevent scouring.

Sanjou and Nezu (2009) experimentally studied the horizontal vortex and secondary flow in meandering compound open channel flows. They stated that the mean velocity distribution between the straight stream and the meandering stream zone is substantially different. Several horizontal vortices occurred locally in a wide zone, including over the floodplains. The rotational direction of these vortices corresponds to the velocity shear at the vortex core. They may be inclined to the channel bed because the convection velocity varies in the vertical direction, and they then disappear as they have a short life span. Moreover, the secondary flows take place in the effective circulation motion in the main channel region. Vertical downstream flow from the abutment upstream also creates tailwater vortexes and horseshoe vortexes (Sanjou and Nezu, 2009).

Cardoso and Fael (2009) found that, at the end of tests they conducted under clear-water flow conditions, the scour would be negligible if the thickness of the riprap cover layer placed on the bridge abutment is equal to at least six times the riprap diameter. Ballio et al. (2009) examined the effect of a local scour around the bridge abutment over time and the effect of convergence in the abutment under clear-water scour flow conditions. Masjedi et al. (2010) investigated the phenomenon of scouring with a collar applied to the bridge pier in a $180^{\circ}$ curved channel. This continued to create a scour due to the downstream effect and a complex vortex system formed via the interaction with the approaching stream. This vortex system extended towards the downstream along the edges of the abutment and is referred to as a horseshoe vortex due to its shape. Thus, the horseshoe vortex developed due to the separation of the flow at the scour hole formed at the downward side as a result of the downstream flow. The horseshoe vortex is similar to the downstream vortex system. As the scour depth increased, the strength of the horseshoe vortex decreased, leading to a decrease in sediment transportation from the abutment. Dehghani et al. (2013) reported that the obstruction caused by a groyne created a horseshoe-shaped vortex around the front and sides of the groyne. Wu et al. (2014) conducted experiments to examine the maximum scour depth under ice cover around bridge abutments. Armor layer grain size has a strong impact on the dimensionless maximum scour depth. As the 
particle size of the armor layer increased, the maximum scour depth decreased. Conversely, as the ice cover roughness increased, the maximum scour depth increased. The relationships between maximum scour depth, water depth, densimetric Froude number, ice cover roughness, and armor layer grain size are derived through dimensionless analysis. Pagliara et al. (2015) studied the scour phenomena in the downstream of log-vanes in straight rivers under clear-water flow conditions. The results demonstrated that the tailwater depth is an important variable in determining the maximum scour depth and the vane angle is an important parameter in predicting the scour parameters. Dimensional analysis allows the derivation of design equations used to estimate the maximum scour depth, maximum length of the scour, and the maximum height and length of the dune.

The existing literature shows that, despite the importance of the abutment of a bridge in a curved channel, little attention has been paid to studying the local scour in such a case. Most studies focus on the scour on bridge abutments located on straight streams. Only a few studies focus on meandered streams. The present study therefore comprised an experimental investigation of the local scour around a bridge abutment located on the inner and outer banks of the curved channel at bend angles of $a=30^{\circ}, 60^{\circ}, 90^{\circ}, 120^{\circ}$, and $150^{\circ}$. The effects of the flow intensity $\left(V / V_{c}\right)$, bridge abutment length $\left(L_{a}\right)$, and bend angle $(a)$ on local scouring were investigated separately and in detail for the inner and outer banks.

\section{Dimensional Analysis}

Dimensions of scour depth formed around a bridge abutment along a curved channel can be expressed as a function of the following parameters;

$d_{\mathrm{se}}=f\left(V, V_{c}, L_{a}, B_{a}, B, S_{o}, \alpha, r_{c}, y, g, d_{50}, \rho_{\mathrm{s}}^{\prime}, \sigma_{g}, \rho, \mu, t, K_{s}\right)(5)$

where $d_{s e}$ is the equilibrium scour depth, $V$ is the mean approach flow velocity, $V_{c}$ is the velocity of approach flow corresponding to the inception of sediment particle motion in the approach flow (the critical velocity), $L_{a}$ is the length of the abutment, $B_{a}$ is the width of the abutment, $B$ is the main channel width, $S_{o}$ is the channel bed slope, $a$ is the angle of bend center, $r_{c}$ is the radius of main channel centerline, $y$ is the water depth, $g$ is the acceleration due to gravity, $d_{50}$ is the location on a non-cohesive sediment bed made of uniform grains with median grain size, $\rho_{\mathrm{s}}^{\prime}\left(=\rho_{\mathrm{S}}-\rho\right)$ is the buoyant sediment density, $\sigma_{\gamma}$ is the geometric standard deviation of the sediment, $\rho$ is the mass density of water, $\mu$ is the dynamic viscosity of the water, $t$ is the scouring time, and $K_{s}$ is the abutment shape factor.

The Buckingham $\Pi$-theorem applied to Eq. (5), choosing $\rho, y$, and $V$ as basic variables, leads to a functional relationship in terms of the dimensionless groups shown in Eq. (6):

$$
\frac{d_{\mathrm{se}}}{y}=f\left(\frac{L_{a}}{y}, \frac{V}{\sqrt{\mathrm{gy}}}, \frac{V}{V_{c}}, \frac{B_{a}}{y}, \frac{B}{y}, \frac{r_{c}}{y}, \frac{\rho_{\mathrm{s}}^{\prime}}{\rho}, \frac{\mathrm{V} \cdot \mathrm{y}}{\nu}, S_{o}, \sigma_{g}, \frac{\mathrm{V} . \mathrm{t}}{y}, \frac{d_{50}}{y}, \alpha, K_{s}\right)(6)
$$

Melville (1995) proposed a shape factor $K_{s}$ to express the effects of different shaped abutments on the scour. He gave $K_{s}=0.75$ for a vertical wall abutment with a semicircular end. In the present study, the experiments were designed for an oblong abutment and therefore $K_{s}$ was constant. In free surface flows, the influence of the Reynolds number in terms of viscous effects on the local scour process can be considered negligible (Melville and Chiew, 1999). The flume has constant slope. The radius of main channel centerline $\left(r_{c}\right)$ in the current study was constant. Therefore, these terms were dropped.

$$
\frac{d_{\mathrm{se}}}{y}=f\left(\frac{L_{a}}{y}, F_{d}=\frac{V}{\sqrt{g\left(\frac{\rho_{\mathrm{s}}^{\prime}}{\rho}\right) d_{50}}}, \frac{V}{V_{c}}, \frac{L_{a}}{B_{a}}, \frac{L_{a}}{B}, \frac{\mathrm{V} . \mathrm{t}}{y}, \alpha\right)(7)
$$

In the equilibrium condition, the increase in dimensions of the scour geometry stops and remains unchanged. Equation (7) can be written as follows:

$$
\frac{d_{\mathrm{se}}}{y}=f\left(\frac{L_{a}}{y}, F_{d}, \frac{V}{V_{c}}, \frac{L_{a}}{B_{a}}, \frac{L_{a}}{B}, \alpha\right)(8)
$$

or

$$
\frac{d_{\mathrm{se}}}{L_{a}}=f\left(\frac{L_{a}}{y}, F_{d}, \frac{V}{V_{c}}, \frac{L_{a}}{B_{a}}, \frac{L_{a}}{B}, \alpha\right)(9)
$$


in which the scour depth is normalized with flow depth and abutment length, as shown in Eqs. (8) and (9).

\section{Experimental Setup and Methodology}

All experiments were conducted in a curved channel with an axis curvature radius of $3 \mathrm{~m}$ at Firat University, Hydraulic Laboratory. The curved channel width was $0.50 \mathrm{~m}$. The main channel depth was $0.50 \mathrm{~m}$. The channel bed slope $(S$ o) was $0.1 \%$. The bridge abutment was placed on the inner and outer walls of the channel with bend angles of $30^{\circ}, 60^{\circ}, 90^{\circ}, 120^{\circ}$, and $150^{\circ}$ in section I (see Fig

. 2). Bridge abutments placed on the curved channel were produced using plexiglass material. The oblong bridge abutment was $B_{a}=8 \mathrm{~cm}$ wide, $50 \mathrm{~cm}$ high, and three different abutment lengths were selected: $L_{a}=$ 8,10 , and $12 \mathrm{~cm}$. The tip of the abutment was semicircular with a diameter of $8 \mathrm{~cm}$ (Fig. 3).

Fig. 2. Experimental setup

Fig. 3. Oblong bridge abutment dimensions and the abutment placed in the channel

Quartz sand $0.25 \mathrm{~m}$ in height was placed between the $1^{\text {st }}$ and $2^{\text {nd }}$ sills on the main channel, as illustrated in Fig. 2. The uniformly graded sands used in the experiments had median diameters $d{ }_{50}=1.16,1.34$, and $3.72 \mathrm{~mm}$ with threshold shear velocities $u_{c}^{*}=2.725,3.046$ and $5.708 \mathrm{~cm} / \mathrm{s}$, respectively. The uniformity coefficient $\left(C_{u}=d_{60} / d_{10}\right)$ for the sediment used was less than 3 . Sediments with $C_{u}[?] 3$ were considered to be uniform. The geometric standard deviation $\sigma_{\gamma}$ of the sediment given by $\left(d_{84.1} / d_{15.9}\right)^{0.5}$ was less than 1.4 for uniformly graded sediment.

Prior to each experiment, the sand was mixed and the bed was leveled. The desired discharge was adjusted with a valve and measured using a Siemens brand electromagnetic flowmeter with $\pm 0.01 \mathrm{~L} / \mathrm{s}$ sensitivity. Water for the curved channel was supplied through a pipe from a sump. A Mitutoyo brand digital point gauge with $\pm 0.01 \mathrm{~mm}$ sensitivity was used to measure water level and bed topography. Bed topography variations were measured using the digital point gauge in the abutment region. Thus, readings could be taken in both $x$ and $y$ directions using a special type of measurement car that moved on rails. Figures 4 and 5 show the reading spots along the curved channel and the scouring phenomenon in 3D bed topography.

Fig. 4. The bed topography measurement spots on the inner bank

Fig. 5. 3D presentation of the scour formed at the bed topography measurement spots on the inner bank and post-experimental image

The bridge abutment was placed in a curved channel on the inner and outer banks at $30^{\circ}, 60^{\circ}, 90^{\circ}, 120^{\circ}$, and $150^{\circ}$ bend angles. A series of experiments were then conducted for different abutment lengths and different flow rates under clear-water flow conditions. The main objective of these experiments was to examine the local scour depths around different length oblong abutments placed on the inner and outer banks of the channel bend. The required flow value and flow depth for predetermined flow rates were then obtained. In the first experiment, the flow rate was adjusted rapidly using the valve and flowmeter on the main channel. The butterfly valve at the end of the curved channel was initially closed and then opened slowly after the flow and flow depths were determined and flow conditions were established. The test period began after the predetermined flow depth was established. Scour depths were investigated over time and bed topography formed around the abutment was obtained when the equilibrium scour depth was established. The changes in scouring in a curved channel were examined using maximum scour depths measured as dimensionless parameters $d_{s} / L_{a}$ and $t / t_{m}$ after the bridge abutment was put in place.

The critical velocity $\left(V_{c}\right)$ values that could set the bed material in motion at various flow depths were obtained using Eq. (6) given by Melville (1997),

$V_{c} / u_{c}^{*}=5.75 \log \left(5.53 \mathrm{y} / d_{50}\right)(10)$

where $u_{c}^{*}$ is the critical shear velocity. Melville (1997) proposed Eq. (10) for $u_{c}^{*}(\mathrm{~m} / \mathrm{s})$ for $1 m m<d_{50}<$ $100 \mathrm{~mm}$. 
$u_{c}^{*}=0.0305 d_{50}^{0.5}-0.0065 d_{50}^{-1}(11)$

Critical shear velocity $\left(u_{c}^{*}\right)$ was calculated as $0.02725 \mathrm{~m} / \mathrm{s}$ from Eq. (11) for $d_{50}=1.16 \mathrm{~mm}$. Equation (12) was obtained for $d_{50}=1.16 \mathrm{~mm}$. The critical velocity equations were similarly calculated for other median diameters. Equation (12) was tested and verified in the experimental setup.

$V_{c}=0.1567 \log (4767 y)$

\section{Analysis of Results}

2. The impact of flow intensity on scour depth

In the literature, clear-water scour experiments are preferred to live bed scour experiments as they provide a steady state, greater scour depth, and a clearer idea for designers (Raudkivi and Ettema, 1983; Coleman et al., 2003; Rajkumar and Dey, 2005; Pagliara et al., 2015).

In Fig. 6 (a-f), the change in $t / t_{m}$ relative to $d_{s} / L_{a}$ was plotted for different flow intensities $V / V_{c}$. This graph is provided for bend angle $a=60^{\circ}$ and for both inner and outer banks and different abutment lengths. In the case of clear-water scouring, it was observed that the dimensionless scour depth increased in line with the increase in flow intensity. The scour depth initially rapidly increased over time, after which it continued asymptotically until, eventually, the change in scour depth was minimal. Thus, the scour depth reached an equilibrium. The time taken to achieve this depended on the dimensionless flow intensity $\left(V / V_{c}\right)$ and the dimensionless particle size $\left(d_{50} / y\right)$. Most of the maximum scour depth occurred up until $t / t_{m}$ was equal to 0.2. When $t / t_{m}$ was0.6, the asymptote was formed. As shown in Fig. 6 (a-f), scouring was higher on the outer bank. The impact of the secondary flow was extremely significant in this problem. One of the main reasons why the curved converging channel can be successfully used as a sediment excluder is that the secondary flow, which develops upstream from the diversion, is strong enough to move any particles traveling along the bed towards the inside wall and away from the canal entrance. Damaskinidou-Georgiadou and Smith (1986) found that the maximum longitudinal velocities occurred in the inside bank, and the values of mean longitudinal velocity approximated to a free vortex along the channel.

Fig. 6. Changes in $t / t_{m}$ and $d_{s} / L_{a}$ based on different $V / V_{c}$ values for $a=60^{\circ}$

Figure 6 shows that the effect of the flow intensity $\left(V / V_{c}\right)$ on the maximum scour depth for $60^{\circ}$ was consistent with the literature (Melville and Chiew, 1999). Tsujimoto and Mizukami (1985) reported that the scour depth under clear-water flow conditions initially increased and then continued as an asymptote after a certain period of time. Maximum scour depth also increased in line with increasing flow intensity $\left(V / V_{c}\right.$ ). Table 1 presents the results of the experiment on variations in scour depth due to flow intensity at the curved channel bends at $30^{\circ}, 60^{\circ}, 90^{\circ}, 120^{\circ}$, and $150^{\circ}$ for $d_{50}=1.16 \mathrm{~mm}$. As shown, the maximum scour depth at all corners of the curved channel increased in line with flow intensity.

\section{Table 1}

Changes in scouring based on flow intensity at $30^{\circ}, 60^{\circ}, 90^{\circ}, 120^{\circ}, 150^{\circ}$ angles of the curved channel.

The impact of abutment length on scour depth

As shown in Fig. 7 (a-j), the impact of the abutment length on scouring along the curved channel is different at each bend angle. In a straight channel, scour depth increases as the abutment length increases (Kayaturk, 2005). However, in the present study, the scour depth in the curved channel decreased as the abutment length on the outer bank increased. In general, less scouring was observed for an abutment length of $12 \mathrm{~cm}$. This showed that the scour formed as a result of the velocity distribution at the outer bank of a curved channel decreased in line with a reduction in the effect of secondary flow as the abutment length increased. When the bridge abutment is placed in the curved channels, the scouring at the inner and outer banks differs. Local scour depth occurs more often at the outer bank due to the effect of secondary flow and maximum velocity path while deposition occurs at the inner bank. Therefore, at the outer bank of the curved channels, a local scour takes place due to the effect of both the secondary flow and downflow. As shown in Fig. 7(a-j), the scouring at the outer bank is greater than the scouring at the inner bank. Thus, it is important to know 
in advance the properties of the flow in the curved channel when selecting a hydraulic structure such as a water intake structure.

Fig. 7. Changes in $t / t_{m}$ and $d_{s} / L_{a}$ based on different $L_{a}$ values for $a=30^{\circ}, a=60^{\circ}, a=90^{\circ}, a=120^{\circ}$ and $a$ $=150^{\circ}$

\section{The impact of bend angle on scour depth}

It was generally observed that, for scour depths at bend angles of the $L_{a}=8 \mathrm{~cm}$ abutment located on the outside bank in a $180^{\circ}$ curved channel, the maximum scour increased in line with the increasing bend angle. Thus, maximum scour usually occurs at a $150^{\circ}$ bend angle. This is because the maximum velocity in a linear channel occurs around the channel axis close to the water surface. The local flow slows down when entering the curve and gains momentum after passing the curve turning point. In a 180-degree curved channel, the maximum velocity orbits diverge from the normal orbits, first going towards the inner bank. When $a=$ $45^{\circ}$, they start to flow towards the outer bank and when $a=60^{\circ}$, they start to settle at the outer bank. The maximum velocity orbit located at the outer bank turns towards the channel axis after $a=120^{\circ}$ and can be observed near the channel axis at the curve exit. The scour depths at the bend angles of a $L_{a}=8$ $\mathrm{cm}$ abutment placed on the inner bank of the curved channel demonstrated that the maximum scour also increased in line with increasing bend angle. On the inner bank, the maximum scour occurred at a $150^{\circ}$ bend angle (Fig. 8). Based on all bend angles, a variation of between $5 \%$ and $15 \%$ was observed for the maximum scour depths formed.(Fig. 8).

In the second half of the curved channel, the scour depths formed on the bridge abutments were greater than in the first half. At the entrance of the channel, where the material transferred from the upstream compensates the carried material, there was less scouring at $30^{\circ}$. Therefore, if the bridge abutment is placed at the beginning of the curve, there will be less scour depth.

Fig. 8. Variation on outer and inner bank scour depths for $a=30^{\circ}, a=60^{\circ}, a=90^{\circ}, a=120^{\circ}, a=150^{\circ}$ bend angles.

The active length of the tailwater vortexes is longer than that of the horseshoe vortexes. However, because the velocity of horseshoe vortexes is greater than the velocity of the tailwater vortexes, the maximum scour is observed in the abutment upstream. Another reason for this is that the accumulation of particles unraveling from the upstream face in a downstream direction due to the falling flow intensity. In the present study, the maximum scour occurred around the upstream wall of the abutment (see Fig. 9).

Fig. 9 Variations in scour depth on the inner bank at $8 \mathrm{~cm}$ abutment.

Comparison of outer bank and inner bank scour depths

Figure 10 (a-o). A comparison of inner bank and outer bank maximum scour depths in the curved channel at bend angles of $30^{\circ}, 60^{\circ}, 90^{\circ}, 120^{\circ}$, and $150^{\circ}$ demonstrated that the maximum scour depth in all bend angles of the curved channel was higher on the outer bank than on the inner bank. This was because the material moving as a result of the secondary flow causes scouring on the outer bank and accumulation of the sediment on the inner bank. Sanjou and Nezu (2009) stated that there is a strong relation between the horizontal vortices and secondary flows. Furthermore, Minor et al. (2007) reported that secondary flows are caused by turbulence anisotropy at the wall in narrow channel bends.

Variations in the scour depth between the inner and outer banks of the main channel at bend angles $a=$ $30^{\circ}, 60^{\circ}, 90^{\circ}, 120^{\circ}$ and $150^{\circ}$ of the curved channel (based on the dimensionless parameters denominated with $d_{s} / L_{a}$ on the y-axis and $t / t_{m}$ on the x-axis) are displayed in Figure 11 (a-o). Examination of the scour depths along the curved channel shows that the scour depth at each bend angle was greater on the outer bank than the inner bank. This was due to the formation of secondary and helicoidal flow in the curved channel. The secondary flow also occurs due to the porousness of the wall and pressure oscillations. In meander oscillations, the secondary flow effect is strengthened due to the centrifugal force. The outer bank is scoured while the sediment is accumulated on the inner bank. As described by Onen and Agaccioglu (2013), this is because 
the secondary movement starts before the curve entrance in a curved channel, accelerates in the curvature, and decreases toward the curvature exit. One of the most important characteristics of the curved flow is the helicoidal flow; another is the maximum velocity path motion. The helicoidal flow is caused by friction, and by centrifugal and inertia forces. The helicoidal flow is defined as the ratio of the mean kinetic energy of the secondary action in a given cross-section to the total kinetic energy of the flow. Onen and Agaccioglu (2013) stated that the velocity of fluid particles near the channel bed is significantly delayed by the boundary resistance. Fluid that moves with a lower velocity near the bed is forced to follow a sharper curved orbit to establish an equilibrium between centrifugal and pressure forces; conversely, the orbits of fluid particles closer to the surface move towards the channel bed due to the higher inertia caused by higher speed. To maintain the fluid mass, the water moves towards the bed at the outer bank and towards the surface from the bed at the inner bank. Thus, in addition to the longitudinal velocity component, a radial velocity component perpendicular to the channel axis is formed. This forms the secondary flow in the cross section plan.

Fig. 10 Variation on outer and inner bank scour depths

The variation in dimensionless maximum scour depth with dimensionless time was investigated for different median sediment grain sizes $\left(d_{50}\right)$ and constant abutment length, and for constant flow intensity for values of bend curvature angles, as shown in Fig. 11. This clearly shows that as the grain diameter decreases, the depth of scour increases.

Fig. $11 d_{s} / L_{a}$ versus $t / t_{\mathrm{m}}$ for $d_{50}=1.16, d_{50}=1.34, d_{50}=3.72 \mathrm{~mm}$ : (a) $\alpha=60^{\circ}$, (b) $\alpha=120^{\circ}$

Empirical correlations predicting the equilibrium scour depth were developed for the oblong bridge abutment at the inner banks of the curved channel with bend curvature $a=30^{\circ}, 60^{\circ}, 90^{\circ}, 120^{\circ}$, and $150^{\circ}$. The resulting correlation is given in Eq. (13) and the values of the constants and the correlation coefficients (R) are presented in Table 2. Eq. (14) gives the relation between the inner and outer bank based on the experimental data in the current study. For Eq. (14), the correlation coefficient is 0.98 .

$\left(\frac{d_{\mathrm{se}}}{L_{a}}\right)_{\text {inner bank }}=a\left(\frac{L_{a}}{y}\right)^{b}\left(\frac{V}{V_{c}}\right)^{c}\left(F_{d}\right)^{d},\left(\frac{L_{a}}{B}\right)^{e}\left(\frac{L_{a}}{B_{a}}\right)^{f}(13)$

where $d_{s e}$ is the equilibrium depth $(\mathrm{m}), L_{a}$ is the length of abutment $(\mathrm{m}), y$ is the flow depth $(\mathrm{m}), V$ is the mean flow velocity $(\mathrm{m} / \mathrm{s}), V_{c}$ is the critical velocity $(\mathrm{m} / \mathrm{s}), \mathrm{F}_{d}$ is the densimetric Froude number (-), Bis the width of channel (m), and $B_{a}$ is the width of abutment $(\mathrm{m})$.

$\left(\frac{d_{\mathrm{se}}}{L_{a}}\right)_{\text {outer bank }}=1.45\left(\frac{d_{\mathrm{se}}}{L_{a}}\right)_{\text {inner bank }}(14)$

The predicted equilibrium scour depth $\left(d_{s e}\right)_{\mathrm{p}}$ is compared with the observed equilibrium scour depth $\left(d_{s e}\right.$ )$_{0}$ to yield the average percent error $\epsilon$ as

$\varepsilon=\frac{100}{N} \sum_{i=1}^{N}\left\lfloor\frac{\left(d_{\mathrm{se}}\right)_{o}-\left(d_{\mathrm{se}}\right)_{p}}{\left(d_{\mathrm{se}}\right)_{o}}\right\rfloor(15)$

in which $N$ is the number of data points. The average percent error $\epsilon$ is a function of the constant in the equilibrium scour depth equation. The average percent error values for Eq. (15) are given in Table 2. Good agreement is obtained between the observed equilibrium scour depth and the values computed from the predictive Eq. (13).

\section{Table 2}

Values of constants and correlation coefficients in Eq. (12)

Table 3 presents a summary of the experiment conditions and the results obtained from the curved channel with an angle of bend curvature of $30^{\circ}$. Also listed in Table 3 are the data obtained by Lim (1997), Dongol (1994), Rajaratnam (1983), and Liu et al. (1961). As shown, the experimental conditions and test results in the current study are compatible with those of previous studies.

Table 3 
Maximum equilibrium scour depth data for abutment

The maximum equilibrium scour depth values of the abutment can be compared with those of Melville (1992), Oliveto and Hager (2002), Dey and Barbhuiya (2005), and Lim (1997), as shown in Fig 12. The equations presented by Melville (1992), Oliveto and Hager (2002), Dey and Barbhuiya (2005), and Lim (1997) are for straight channels. As shown in Fig. 12, there is no close agreement between previous studies. However, there is a certain consistency between previous studies and the present study. One of the most important reasons for this is that the experiments were performed in different types of channel. In the curved channels, the flow characteristics are markedly different to those of straight channels.

Fig. 12. Comparison of maximum scour depth computed using Eqs. (1-4) with data of the present study

\section{Conclusions}

The local scours that occur around the bridge abutments on outer and inner banks in a curved channel were experimentally examined under clear-water flow conditions. Based on the findings, the conclusions are as follows.

- Maximum scour depth increased in line with the increase in flow intensity.

- The maximum scour depth usually decreased as the abutment length on the inner and outer banks in a curved channel increased. The abutment length is thus an important factor for maximum scour depth.

- The maximum scour depth around the abutment located on the outer bank in the curved channel was greater than the scour depth formed on the inner bank. The maximum scour depth around the abutments placed on the outer bank was 1.45 times the scour depth on the inner bank.

- In the curved channel, there were differences in maximum scour depth at different bend angles. This ranged between $5-15 \%$.

- The location of the maximum scour was at the abutment upstream. The scour depth at the abutment upstream was higher than the scour depth at the abutment downstream.

- At the channel entrance, there was less scouring on the first angle of the curve (at $30^{\circ}$ ) because the material from the upstream compensated for the transported material. Therefore, if a bridge is placed in the first half of the curved channel, there is likely to be less scouring on the abutments.

\section{Acknowledgments}

We would like to express our gratitude to Raif CICEK (Civil Engineer) and Muhammet KARTAL (Technician of Hydraulic Laboratory) for their assistance during the experiments.

\section{Notations}

$B$ width of channel (L)

$B_{a}$ width of abutment (L)

$C_{u}$ uniformity coefficient for sediment $\left(\mathrm{M}^{0} \mathrm{~L}^{0} \mathrm{~T}^{0}\right)$

$d_{s}$ depth of scour below initial bed level (L)

$d_{s e}$ equilibrium scour depth below mean bed level (L)

$\left(d_{s}\right)_{\max }$ maximum scour depth (L)

$d_{15.9} 15.9 \%$ by weight of sediment is finer than that indicated (L)

$d_{50}$ median size of bed material (L)

$d_{84.1} 84.1 \%$ by weight of sediment is finer than that indicated (L)

$\mathrm{F}_{1}$ Froude number of approach flow $\left(\mathrm{M}^{0} \mathrm{~L}^{0} \mathrm{~T}^{0}\right)$

$\mathrm{F}_{d}$ densimetric Froude number $\left(\mathrm{M}^{0} \mathrm{~L}^{0} \mathrm{~T}^{0}\right)$ 
$g$ acceleration due to gravity $\left(\mathrm{LT}^{-2}\right)$

$h_{d}$ hydraulic depth (area/top width) (L)

$K_{s}$ abutment shape factor $\left(\mathrm{M}^{0} \mathrm{~L}^{0} \mathrm{~T}^{0}\right)$

$L_{a}$ length of abutment $(\mathrm{L})$

$Q$ discharge $\left(\mathrm{L}^{3} \mathrm{~T}^{-1}\right)$

$r_{c}$ centerline radius of channel (L)

$S_{o}$ channel slope $\left(\mathrm{M}^{0} \mathrm{~L}^{0} \mathrm{~T}^{0}\right)$

$t$ time $(\mathrm{T})$

$t_{m}$ maximum experiment time $(\mathrm{T})$

$u_{c}^{*}$ critical shear velocity $\left(\mathrm{LT}^{-1}\right)$

$V$ mean flow velocity $\left(\mathrm{LT}^{-1}\right)$

$V_{c}$ velocity of approach flow corresponding to inception of sediment particle motion in approach $\left(\mathrm{LT}^{-1}\right)$

$y$ flow depth (L)

aangle of bend curvature $\left(^{\circ}\right)$

$\mu$ dynamic viscosity of water $\left(\mathrm{L}^{2} \mathrm{~T}^{-1}\right)$

$\rho$ mass density of water $\left(\mathrm{ML}^{-3}\right)$

$\rho_{\mathrm{S}}$ sediment density $\left(\mathrm{ML}^{-3}\right)$

$\sigma_{\gamma}$ geometric standard deviation of particle size distribution $\left(\mathrm{M}^{0} \mathrm{~L}^{0} \mathrm{~T}^{0}\right)$

\section{References}

Azamathulla, H. M. (2012). Gene expression programming for prediction of scour depth downstream of sills. Journal of Hydrology, 460, 156-159.

Ballio F, Teruzzi A, Radice A (2009) Constriction effects in clear-water scour at abutments. Journal of Hydraulic Engineering 135(2):140-145, DOI: 10.1061/(ASCE)0733-9429(2009)135:2(140)

Barbhuiya AK, Dey S (2004) Local scour at abutments: A review. Sadhana 29(5):449-476, DOI: 10.1007/BF02703255

Cardoso AH, Bettess R (1999) Effects of time and channel geometry on scour at bridge abutments. Journal of Hydraulic Engineering 125(4):388-399, DOI: 10.1061/(ASCE)0733-9429(1999)125:4(388)

Cardoso AH, Fael, CMS (2009) Protecting vertical wall abutments with riprap mattresses. Journal of Hydraulic Engineering 135(6):457-465, DOI: 10.1061/(ASCE)HY.1943-7900.0000040

Coleman SE, Lauchlan CS, Melville BW (2003) Clear-water scour development at bridge abutments. Journal of Hydraulic Research, 41(5):521-531, DOI: 10.1080/00221680309499997

Damaskinidou-Georgiadou A, Smith KVH (1986) Flow in curved converging channel. Journal of Hydraulic Engineering 112(6):476-496, DOI: 10.1061/(ASCE)0733-9429(1986)112:6(476)

Dey S, Barbhuiya AK (2005) Turbulent flow field in a scour hole at a semicircular abutment. Canadian Journal of Civil Engineering 32(1):213-232, DOI: 10.1139/L04-082

Dongol DMS (1994) Local scour at bridge abutments Rep. No. 544, School of Engrg., Univ. of Auckland, Auckland, New Zeland 
Kandasamy JK, Melville BW (1998) Maximum local scour depth at bridge piers and abutments. Journal of Hydraulic Engineering 36(2):183-197, DOI: 10.1080/00221689809498632

Kayaturk SY (2005) Scour and scour protection at bridge abutments, Ph.D. Thesis, The Graduate School of Natural and Applied Sciences of Middle East Technical University, Ankara

Kothyari UC, Hager WH, Oliveto G (2007) Generalized approach for clear-water scour at bridge foundations elements. Journal of Hydraulic Engineering 133(11):1229-1240, DOI: 10.1061/(ASCE)07339429(2007)133:11(1229)

Leopold LB, Wolman MG (1957) River channel patterns: braided, meandering, and straight. US Government Printing Office.

Lim SY (1997) Equilibrium clear-water scour around an abutment. Journal of Hydraulic Engineering, 123(3):237-243, DOI: 10.1061/(ASCE)0733-9429(1997)123:3(237)

Liu HK, Chang FM, Skinner MM (1961) Effect of bridge constriction on scour and backwater. CER; 60-22.

Masjedi A, Bejestan MS, Efsandi A (2010) Reduction of local scour at a bridge pier fitted with a collar in a 180 degree flume bend. Journal of Hydrodynamics 22(5):646-650, DOI: 10.1016/S1001-6058(10)60012-1

Melville BW (1992) Local scour at bridge abutments. Journal of Hydraulic Engineering ASCE 118(4):615631, DOI: 10.1061/(ASCE)0733-9429(1992)118:4(615)

Melville BW (1995) Bridge abutment scour in compound channels. Journal of Hydraulic Engineering 121(12):863-868, DOI: 10.1061/(ASCE)0733-9429(1995)121:12(863)

Melville, B.W. (1997) Pier and abutment scour: Integrated approach. Journal of Hydraulic Engineering 123(2):125-136, DOI: 10.1061/(ASCE)0733-9429(1997)123:2(125)

Melville BW, Chiew YM (1999) Time scale for local scour at bridge piers. Journal of Hydraulic Engineering 125(1):59-65, DOI: 10.1061/(ASCE)0733-9429(1999)125:1(59)

Minor B, Rennie CD, Townsend RD (2007) "Barbs" for river bend bank protection: application of a threedimensional numerical model. Canadian Journal of Civil Engineering 34(9):1087-1095, DOI: 10.1139/L07-088

Oliveto G, Hager WH (2002) Temporal evolution of clear-water pier and abutment scour. Journal of Hydraulic Engineering 128(9):811-820, DOI: 10.1061/(ASCE)0733-9429(2002)128:9(811)

Onen F, Agaccioglu H (2013) Live bed scour at a side-weir intersection located on an alluvial channel. Irrigation and Drainage 62(4):488-500, DOI: 10.1002/ird.1749

Pagliara S, Sagvand H, Kurdistani SM (2015) Log-vane scour in clear-water condition. River Research and Applications 31(9):1176-1182, DOI: 10.1002/rra.2799

Rajaratnam N, Nwachukwu BA (1983) Flow near groin-like structures. Journal of Hydraulic Engineering 109(3):463-480, DOI: 10.1061/(ASCE)0733-9429(1983)109:3(463)

Rajkumar RV, Dey S (2005) Clear-water scour at bridge piers in fine and medium gravel bed. Canadian Journal of Civil Engineering 32(4):775-781, DOI: 10.1139/L05-022

Raudkivi AJ, Ettema R (1983) Clear-Water Scour around Cylindrical Piers. Journal of Hydraulic Engineering 109(3):338-350, DOI: 10.1061/(ASCE)0733-9429(1983)109:3(338)

Rosgen DL (1994) A classification of natural rivers. Catena 22(3):169-199, DOI: 10.1016/0341$8162(94) 900019$

Sanjou M, Nezu I (2009) Turbulence structure and coherent motion in meandering compound open-channel flows. Journal of Hydraulic Research 47(5):598-610, DOI: 10.3826/jhr.2009.3485 
Seckin G (2004) A simple formula for estimating backwater at bridge constrictions. Canadian Journal of Civil Engineering 31(4):561-568, DOI: 10.1139/L04-024

Urroz GE, Schaefer J, Ettema R (1994) Bridge-pier location and ice conveyance in curved channels. Journal of Cold Regions Engineering 8(2):66-72, DOI: 10.1061/(ASCE)0887-381X(1994)8:2(66)

Tsujimoto T, Mizukami T (1985) Effect of migration to local scour around a bridge pier. Memoirs, Faculty of Tecnology, Kazanawa University, 19(1):25-34

Wu P, Hirshfield F, Sui J (2014) Armour layer analysis of local scour around bridge abutments under ice cover. River Research and Applications 31(6):736-746, DOI: 10.1002/rra.2771

Yanmaz M, Kose O (2007) Time-wise variation of scouring at bridge abutments. Sadhana 32(3):199-213, DOI: $10.1007 / \mathrm{s} 12046-007-0018-6$

\section{Hosted file}

Data Sharing Policy Wiley.docx available at https://authorea.com/users/328263/articles/ 455652-local-scour-at-a-bridge-abutment-along-a-curved-channel

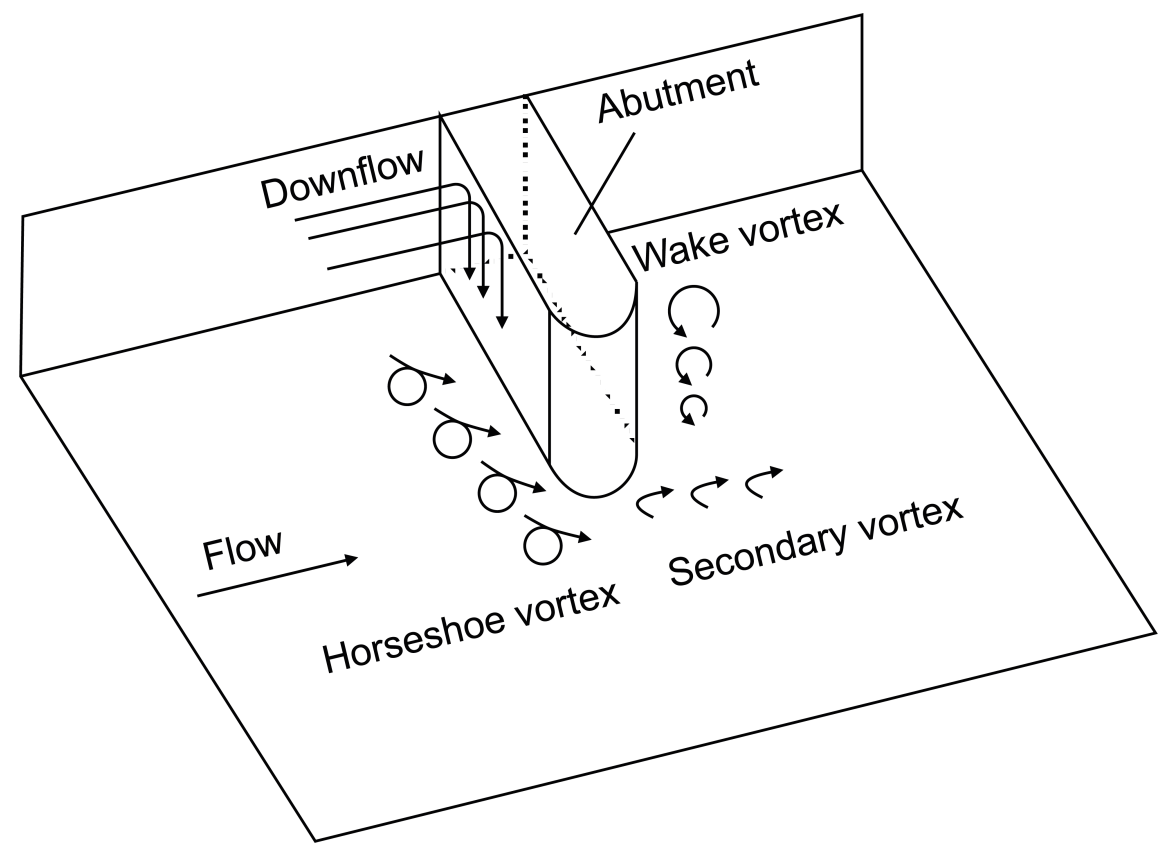


All dimensions are in meters.
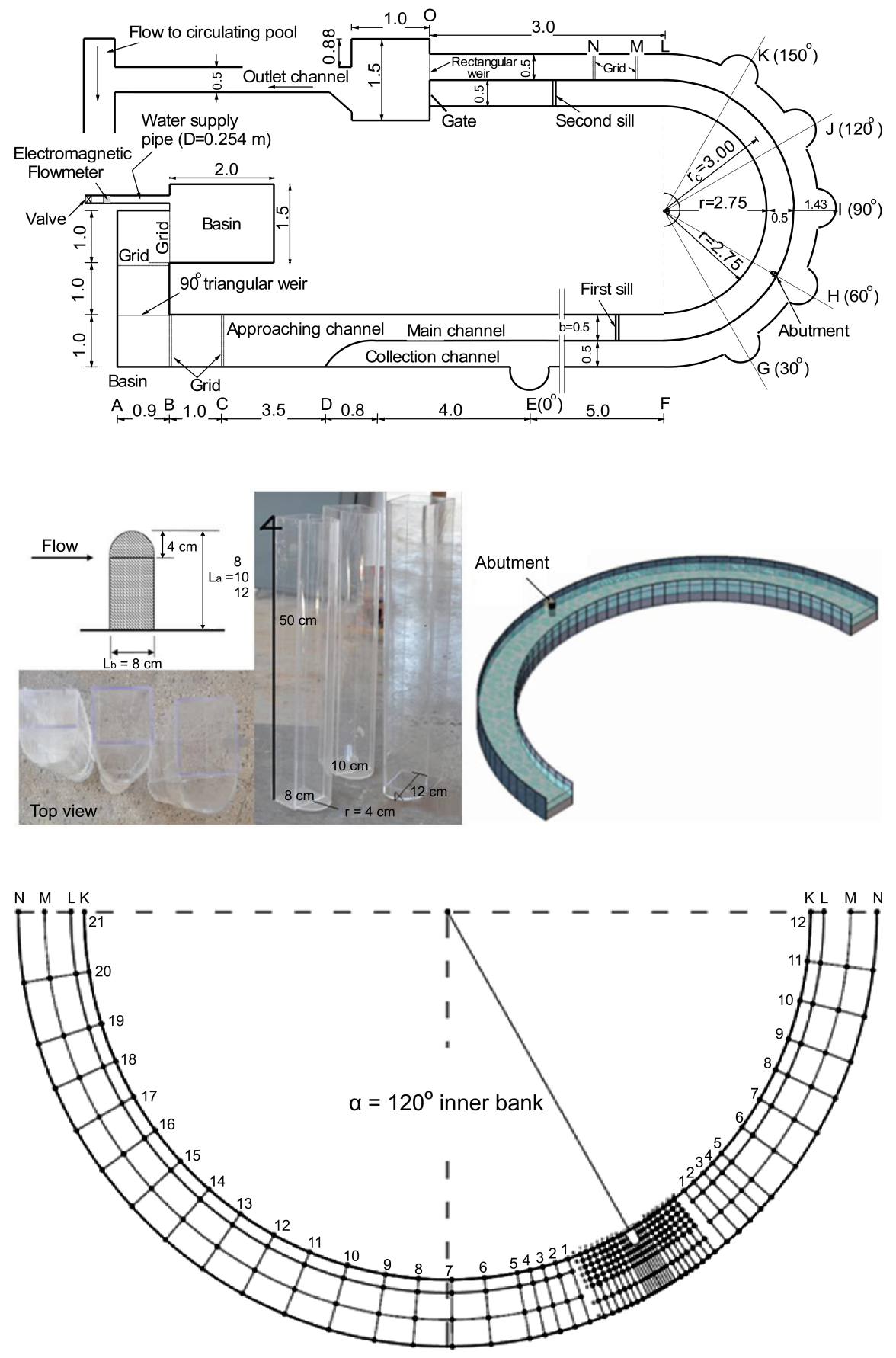

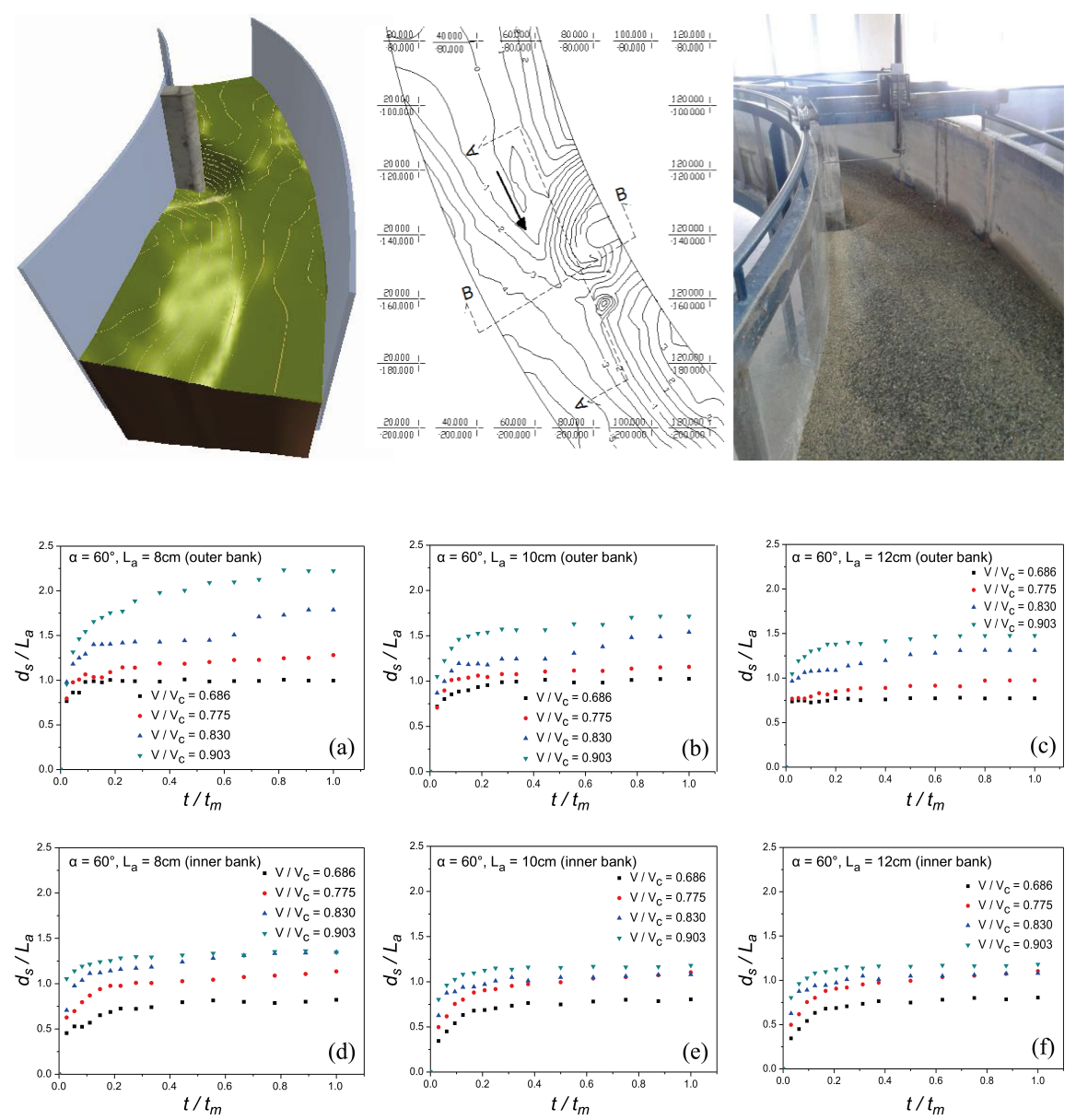

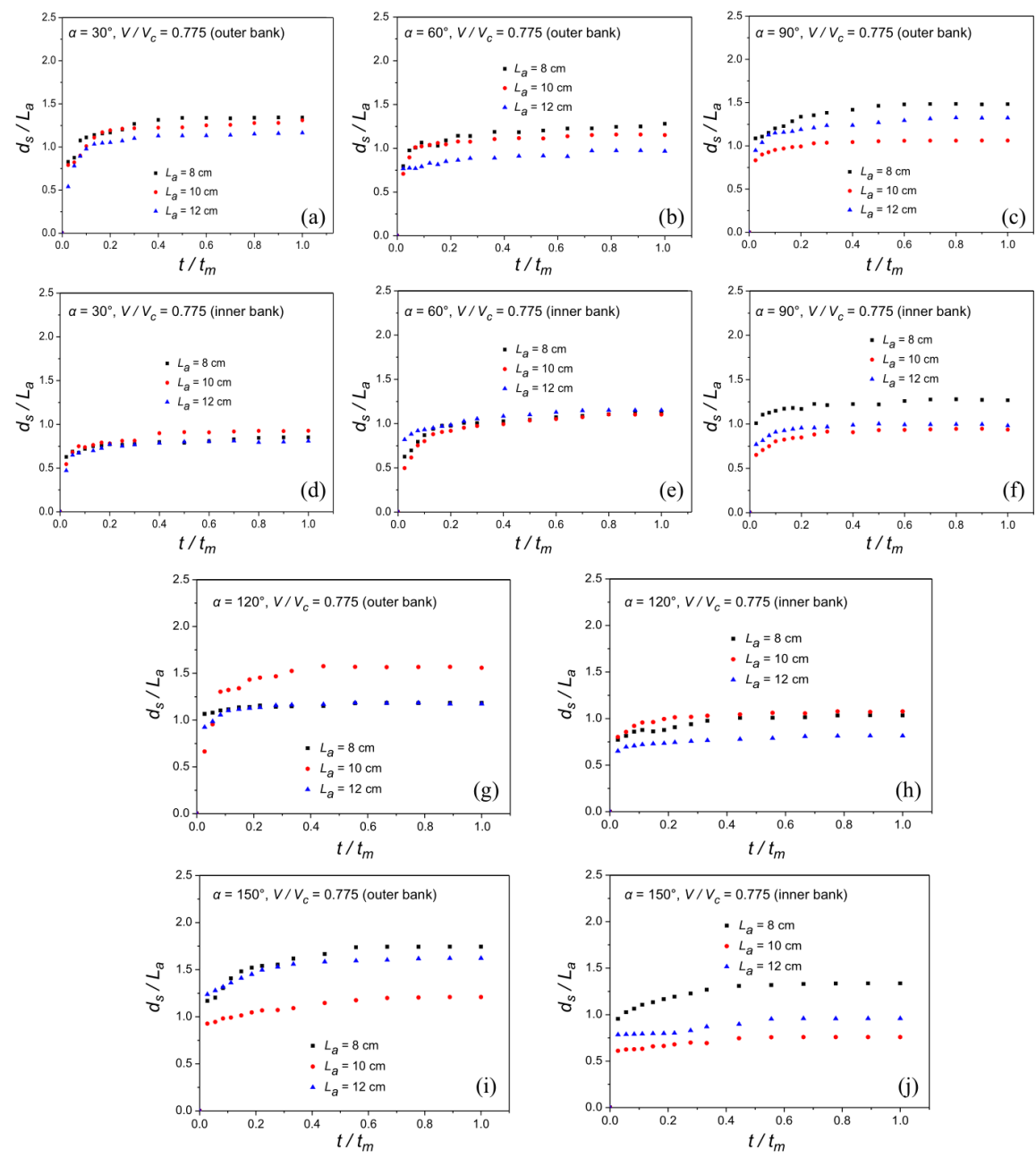

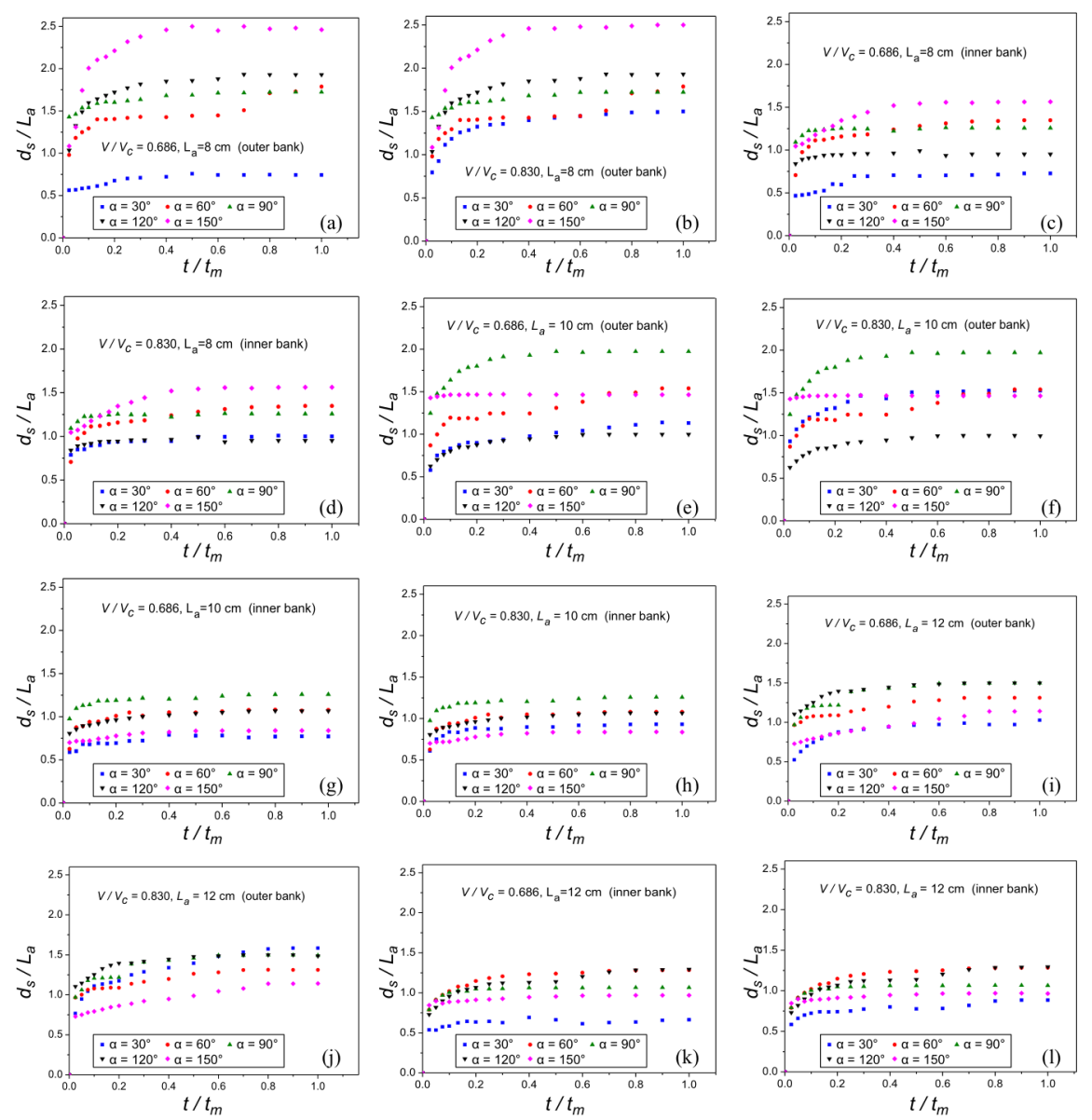

\section{$8 \mathrm{~cm}$ inner bank, $V / V c=0.903\left(\alpha=60^{\circ}\right)$}

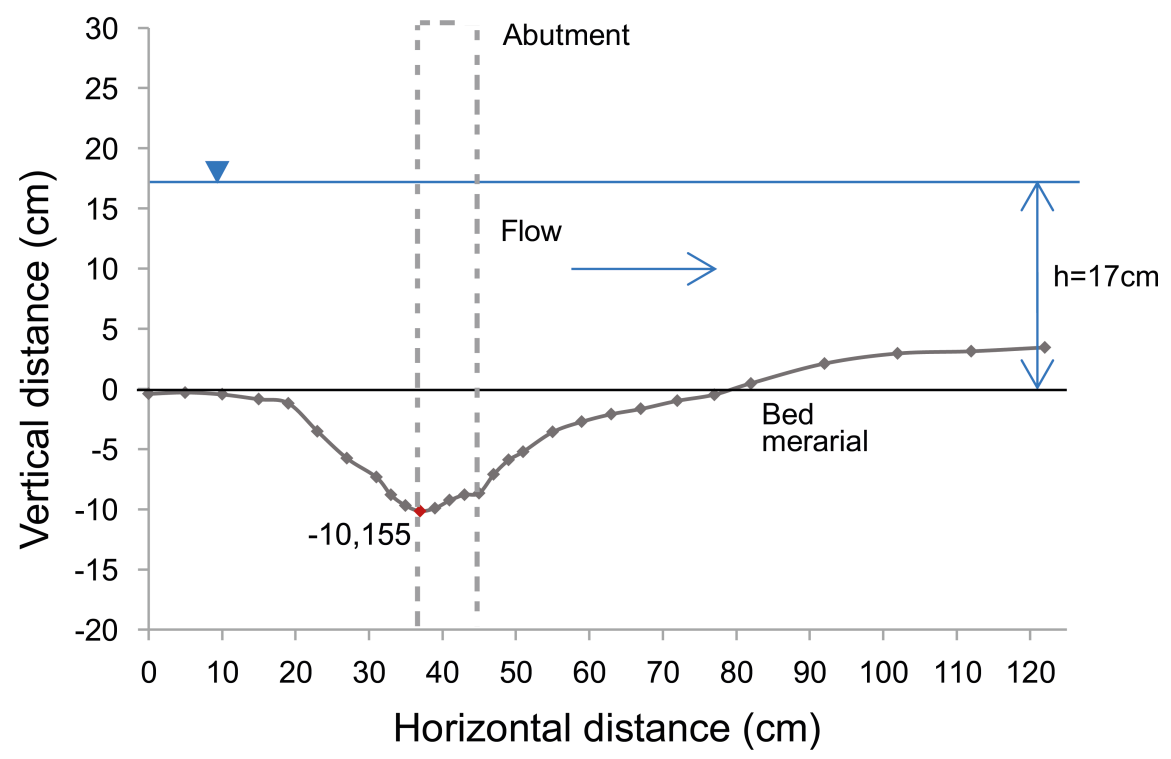



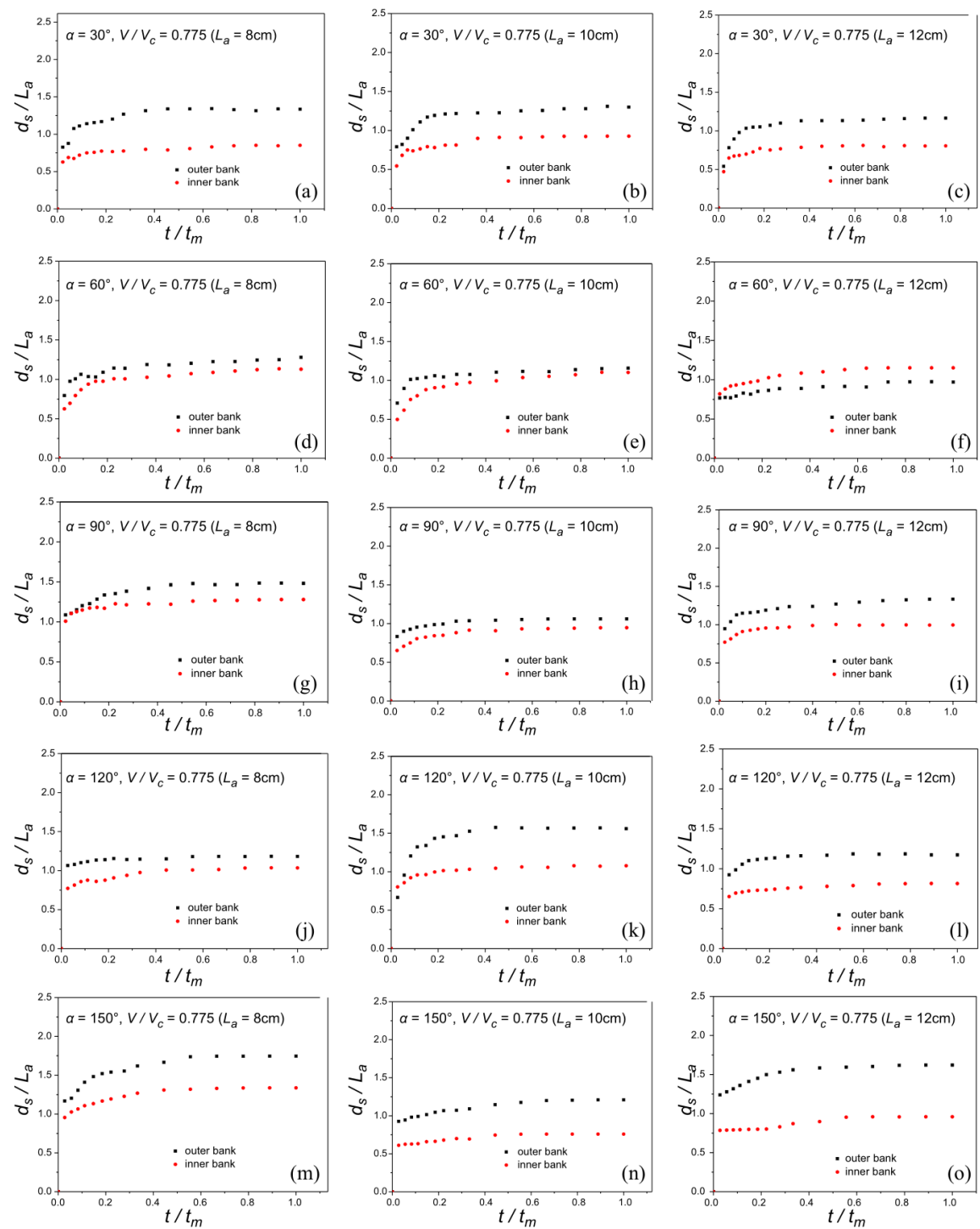

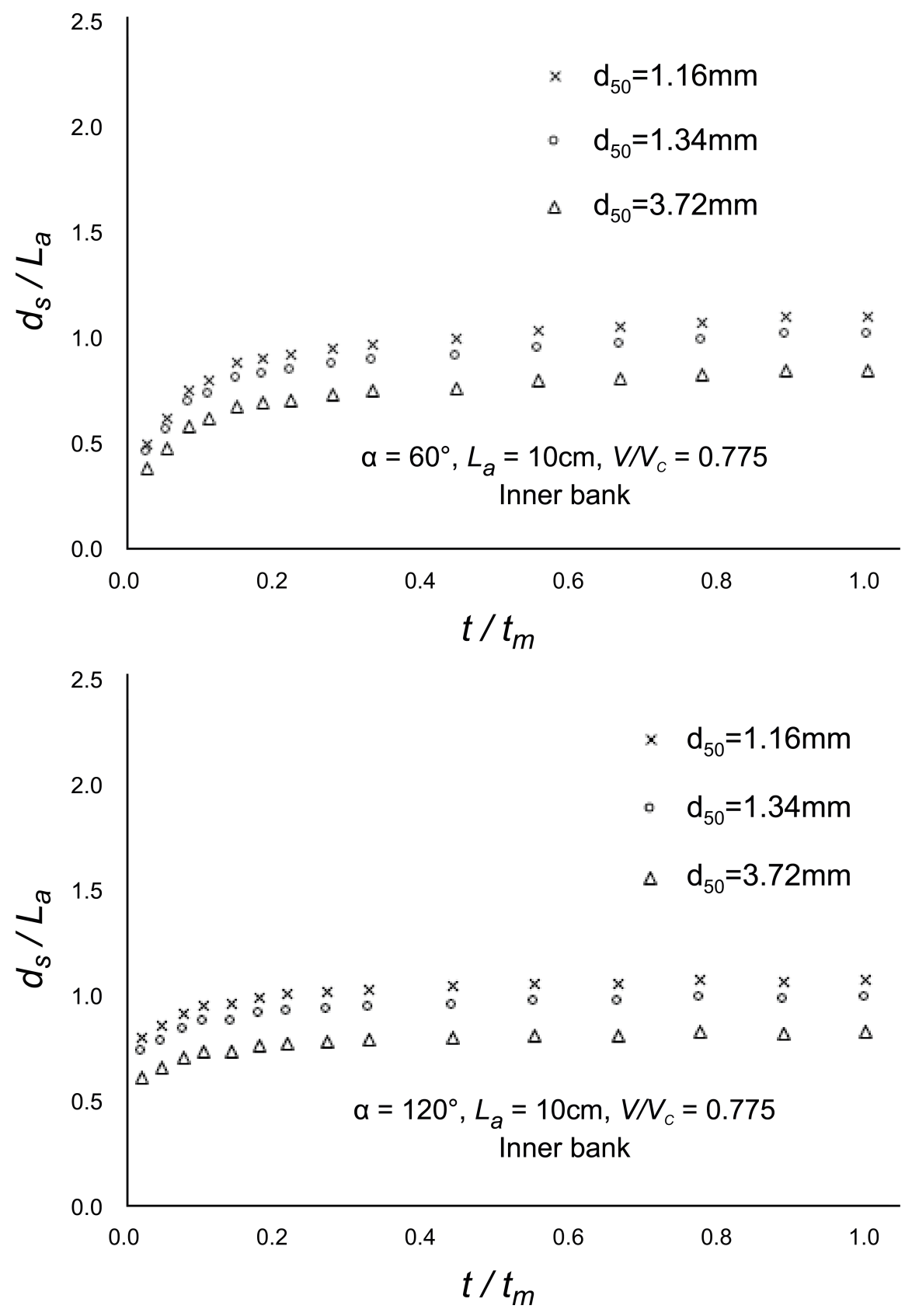


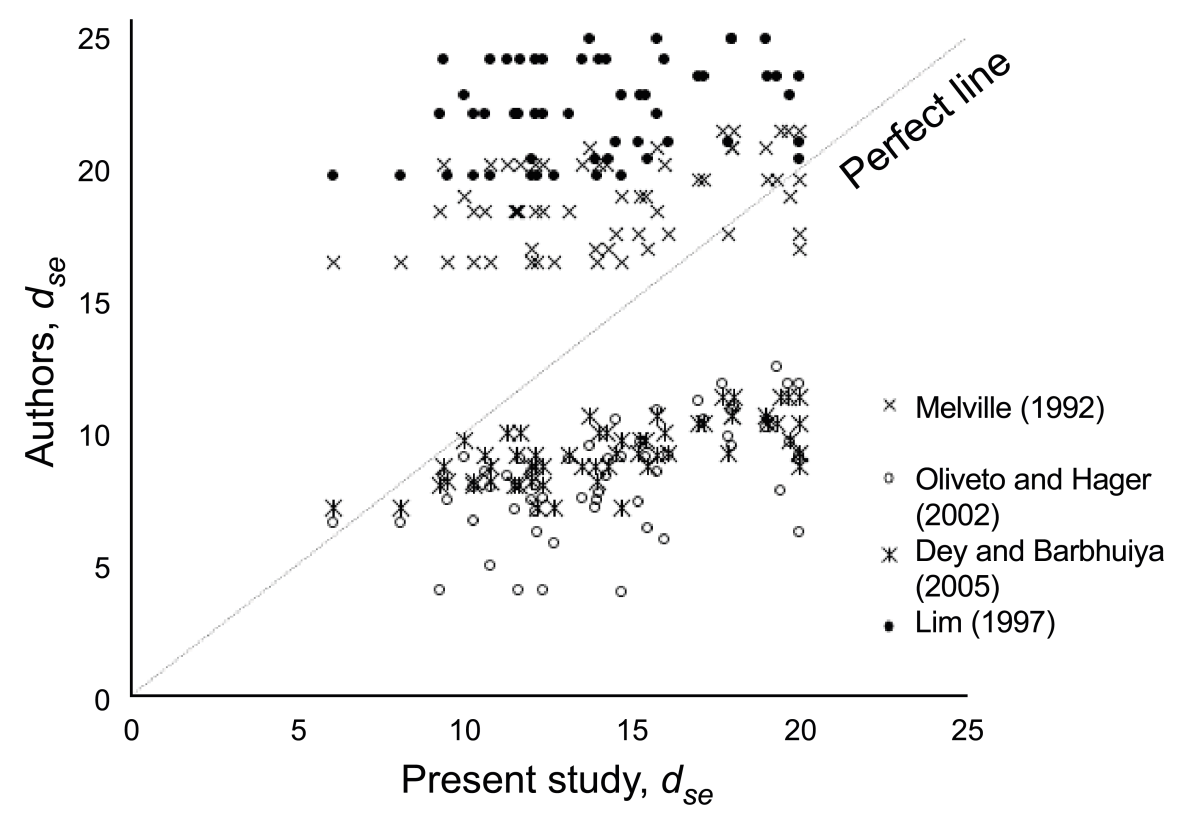

\section{Hosted file}

Table 1.docx available at https://authorea.com/users/328263/articles/455652-local-scour-ata-bridge-abutment-along-a-curved-channel

\section{Hosted file}

Table 2.docx available at https://authorea.com/users/328263/articles/455652-local-scour-ata-bridge-abutment-along-a-curved-channel

\section{Hosted file}

Table 3.docx available at https://authorea.com/users/328263/articles/455652-local-scour-ata-bridge-abutment-along-a-curved-channel 